\title{
Acessibilidade digital em tempos de ensino remoto
}

\author{
Accessibility in times of remote teaching \\ Accesibilidad digital en tiempos de enseñanza a distancia
}

Recebido: 12/04/2021 | Revisado: 17/04/2021 | Aceito: 20/04/2021 | Publicado: 21/04/2021

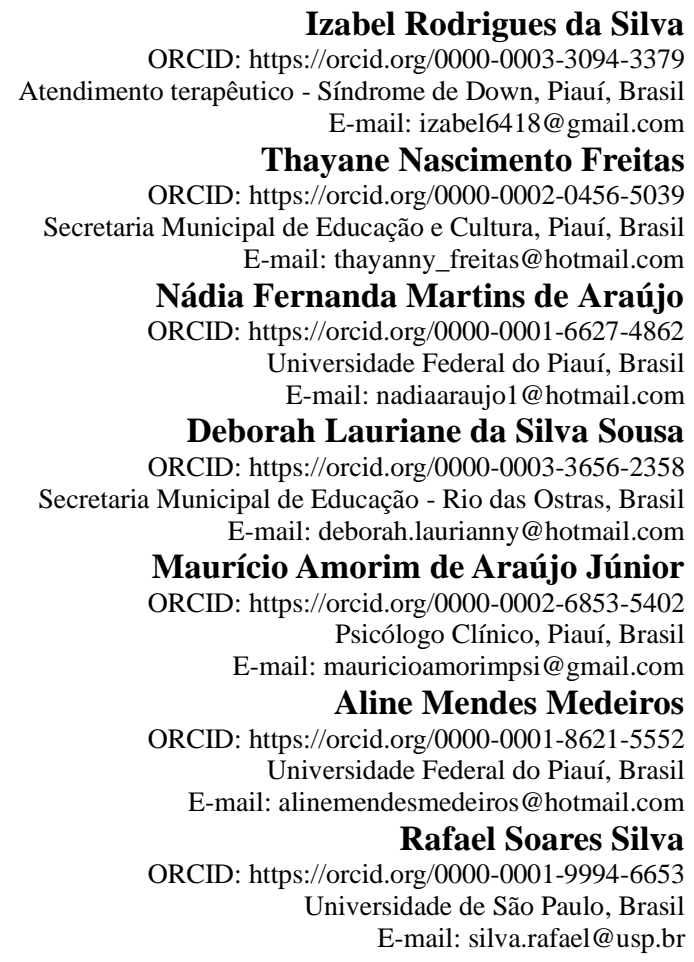

\section{Resumo}

Acessibilidade digital é um mecanismo de alcance a todo e qualquer conteúdo na web em que todas as pessoas devem ter sem a ajuda de outrem, independentemente de suas necessidades. Os recursos virtuais incorporam aspectos que envolvem compreensão, interação e navegação. Desde a virada do século, no começo dos anos 2000, ouvimos que estamos vivendo a era digital. Já quase 21 anos depois, nos vemos cada vez mais imersos na tecnologia, agora mais do que nunca potencializadas pelo isolamento social. Nesse sentido, o processo ensino-aprendizagem tem se tornado cada vez mais desafiador. Pautado nessas questões, temos como objetivo analisar os aspectos legais que abordam sobre a acessibilidade, considerando o contexto de ensino remoto vivenciado a partir das Tecnologias Digitais da Informação e Comunicação. Dessa forma, devido à natureza dos objetivos firmados neste trabalho entendemos que a pesquisa é de abordagem qualitativa, e de natureza metodológica, exploratória e bibliográfica. Os resultados apontam que toda essa situação pandêmica em que nos encontramos é complexa e desafiadora e que diversas dificuldades também se fazem presentes no cenário escolar e que é inegável a necessidade dos docentes e discentes de se reinventarem. Mais ainda, desafia equipes diretivas, professores, estudantes e famílias. No que diz respeito ao ensino remoto, um aspecto a ser considerado é a exclusão digital especialmente da parcela da população que apresenta alguma deficiência, pois a tecnologia digital também pode alcançar as pessoas com deficiências, ao passo que existem aplicativos, softwares e equipamentos que possibilitam a acessibilidade a informação, entretenimento, sociabilidade entre outros benefícios. Enfim, as escolas devem problematizar e repensar uma forma de ensinar e aprender e a tecnologia pode e deve ser uma aliada do ensino-aprendizagem e ser capaz de proporcionar diversos benefícios. Assim, a expectativa é que seu uso se torne comum.

Palavras-chave: Acessibilidade; Acessibilidade Digital; Ensino Remoto.

\section{Abstract}

Digital accessibility is a mechanism for reaching any and all content on the web in which all people must have the help of others, regardless of their need. The virtual resources incorporate aspects that involve understanding, interaction and navigation. Since the turn of the century, in the early 2000 s, we have heard that we are living in the 
digital age. Almost 21 years later, we find ourselves increasingly immersed in technology, now more than ever enhanced by social isolation. In this sense, the teaching-learning process has become increasingly challenging. Based on these issues, we aim to analyze the legal aspects that address accessibility, considering the context of remote education experienced from the Digital Technologies of Information and Communication. Thus, due to the nature of the objectives established in this work, we understand that the research is of a qualitative approach, and of a methodological, exploratory and bibliographic nature. The results show that all this pandemic situation in which we find ourselves is complex and challenging and that several difficulties are also present in the school scenario and that the need for teachers and students to reinvent themselves is undeniable. Furthermore, it challenges management teams, teachers, students and families. With regard to remote education, one aspect to be considered is a digital exclusion especially of the portion of the population that has some disability, as digital technology can also reach people with disabilities, while there are applications, software and equipment that enable accessibility to information, entertainment, sociability and other benefits. Anyway, schools must problematize and rethink a way of using and learning technology can and must be an ally of teaching-learning and be able to provide several benefits. Thus, the expectation is that its use will become common.

Keywords: Accessibility; Digital Accessibility; Remote Teaching.

\section{Resumen}

La accesibilidad digital es un mecanismo para llegar a todos y cada uno de los contenidos de la web en el que todas las personas deben contar con la ayuda de otras, independientemente de su necesidad. Los recursos virtuales incorporan aspectos que involucran comprensión, interacción y navegación. Desde el cambio de siglo, a principios de la década de 2000, hemos escuchado que vivimos en la era digital. Casi 21 años después, nos encontramos cada vez más inmersos en la tecnología, ahora más que nunca reforzada por el aislamiento social. En este sentido, el proceso de enseñanza-aprendizaje se ha vuelto cada vez más desafiante. A partir de estos temas, pretendemos analizar los aspectos legales que abordan la accesibilidad, considerando el contexto de educación a distancia vivida desde las Tecnologías Digitales de la Información y la Comunicación. Así, por la naturaleza de los objetivos establecidos en este trabajo, entendemos que la investigación es de un enfoque cualitativo, y de carácter metodológico, exploratorio y bibliográfico. Los resultados muestran que toda esta situación pandémica en la que nos encontramos es compleja y desafiante y que varias dificultades también están presentes en el escenario escolar y que es innegable la necesidad de que profesores y alumnos se reinventen. Además, desafía a los equipos de gestión, profesores, alumnos y familias. Con respecto a la educación a distancia, un aspecto a considerar es la exclusión digital especialmente de la porción de la población que tiene alguna discapacidad, ya que la tecnología digital también puede llegar a las personas con discapacidad, mientras que existen aplicaciones, software y equipos que permiten el acceso a la información, entretenimiento, sociabilidad y otros beneficios. En definitiva, las escuelas deben problematizar y repensar una forma de usar y aprender la tecnología que puede y debe ser un aliado de la enseñanza y el aprendizaje y poder brindar varios beneficios. Por lo tanto, la expectativa es que su uso se vuelva común.

Palabras clave: Accesibilidad; Accesibilidad Digital; Enseñanza Remota.

\section{Introdução}

O ano é 2021. O mundo inteiro conectado através da tecnologia, surpreendidos por uma crise global. Estamos vivendo num isolamento social o que restringe a participação em atividades rotineiras. As pessoas se veem isoladas fisicamente, com sua mobilidade reduzida, devida a necessidade de evitar aglomerações para conter disseminação da doença que assola essa crise. Repensar novos modos de se comunicar, conviver, estudar e trabalhar tem sido inerente a todos, nesse cenário pandêmico. Nesse sentido, a internet, os programas de comunicação e as mídias sociais passam a ser essenciais (Mendes et al. 2020, p. 35).

O Brasil chega a um número inconcebível de mortes pela Covid-19, e a sensação que temos é que o pior ainda está por vir. Parecendo um trem descarrilhado. As ações governamentais dúbias, confusas e improcedentes, geram por vezes a sensação de que tudo isso está longe do fim, trazendo à tona outros problemas, e um deles é a desigualdade social.

Mendes et al. (2020) ressaltam que, quaisquer que sejam as fontes e os dados escolhidos, a desigualdade no Brasil surpreende. E a pandemia da Covid-19 só reforça essa desigualdade. Nessa lógica, ao se tratar de pessoas com deficiência, essa desigualdade potencializa a vulnerabilidade desse contingente populacional, uma vez que estes já se encontravam em um grupo de risco, em desigualdade social e com negação.

Desde os anos 1990, os direitos sociais e educacionais de pessoas com deficiência têm figurado nos debates nacionais 
e internacionais (Pletsch \& Leite, 2017). Discutir a temática Educação Especial e diversidades faz-se necessário, frente aos desafios cotidianos que vivenciamos nos espaços educacionais e sociais. (Silva et al., 2020).

Alguns documentos são de suma importância quando falamos dos direitos da pessoa com deficiência. A Convenção sobre os Direitos das Pessoas com Deficiência da Organização das Nações Unidas que, por meio do Decreto $n^{\circ}$ 6.949, de 25/08/2009, obteve, no Brasil, status de emenda constitucional. Nele se estabelece, no Art. $11^{\circ}$ que os Estados Partes "tomarão todas as medidas necessárias para assegurar a proteção e a segurança de pessoas com deficiência que se encontrarem em situações de risco", inclusive em emergências humanitárias (Brasil, 2009).

Já a Lei Brasileira de Inclusão da Pessoa com Deficiência (LBI), também conhecida como Estatuto da Pessoa com Deficiência (Lei $\mathrm{n}^{\circ}$ 13.146, de 06/07/2015) que estabelece em seu art. $4^{\circ}$ que toda pessoa com deficiência tem direito à igualdade de oportunidades com as demais pessoas, e não sofrerá nenhuma espécie de discriminação em razão de sua condição.

Em face desta lei, o Art. $2^{\circ}$ considera a pessoa com deficiência aquela que tem impedimento de longo prazo de natureza física, mental, intelectual ou sensorial, o qual, em interação com uma ou mais barreiras, pode obstruir sua participação plena e efetiva na sociedade em igualdade de condições com as demais pessoas.

E para que essa participação na sociedade possa ser plena e efetiva como recomenda a lei, um dos aspectos a ser considerado é a acessibilidade. Embora no contexto da pandemia as pessoas com deficiência seguem na luta, com pautas acerca da inclusão, da acessibilidade, entre outras - que não são recentes. Tais pautas dizem respeito ao ativismo por uma justiça pela deficiência, expressão que Mia Mingus $(2011$, 2018) utiliza para sinalizar a centralidade da deficiência na promoção de um mundo acessível, mais justo. Propor uma comunidade mais justa é pautar a acessibilidade como tema central.

Pautado nessas questões apresentadas, temos como objetivo analisar os aspectos legais que abordam sobre a acessibilidade, considerando o contexto de ensino remoto vivenciado, a partir das Tecnologias Digitais da Informação e Comunicação. Com isso, buscamos expor neste texto reflexões que elucidem as condições específicas em que a pessoa com deficiência se encontra, para conseguir está incluído nas dinâmicas educacionais escolares, contemplando o ensino e a aprendizagem.

\subsection{Sobre a Acessibilidade}

No Brasil, a palavra acessibilidade costuma ser associada apenas a questões físicas e arquitetônicas, mas este vocábulo expressa um conjunto de dimensões diversas, complementares e indispensáveis para que haja um processo de efetiva inclusão. É o direito de ir e vir de cada cidadão somado ao fato de tornar acessível todo e qualquer conteúdo, lugar e/ou produto.

Para fins de aplicação desta Lei n $13.146 / 15$ - Art. $3^{\circ}$, considerasse como acessibilidade:

I - Acessibilidade: possibilidade e condição de alcance para utilização, com segurança e autonomia, de espaços, mobiliários, equipamentos urbanos, edificações, transportes, informação e comunicação, inclusive seus sistemas e tecnologias, bem como de outros serviços e instalações abertos ao público, de uso público ou privados de uso coletivo, tanto na zona urbana como na rural, por pessoa com deficiência ou com mobilidade reduzida (Brasil, 2015).

Porém, Glat (2005, p.16) considera que "o crescente reconhecimento da Educação Inclusiva como norma prioritária de atendimento a alunos com necessidades educativas especiais", na prática ainda "não se configura no Brasil como uma proposta educacional amplamente difundida e compartilhada". Mesmo que nos últimos anos tenham sido desenvolvidas algumas experiências promissoras, a maioria das redes de ensino requer condições institucionais necessárias para a 
viabilização da Educação Inclusiva. Em relação às condições institucionais referidas pela autora supracitada, destaca-se a acessibilidade e as suas diversas dimensões.

Acessibilidade, segundo as Leis: 10.098 (Brasil, 2000) e 13.146 (Brasil, 2015), é um direito que garante à pessoa com deficiência ou com mobilidade reduzida viver de forma independente e exercer seus direitos de cidadania e de participação social.

\subsection{Dimensões da acessibilidade}

Conforme a Lei da pessoa com deficiência de 2015, acessibilidade é entendida como:

possibilidade e condição de alcance, percepção e entendimento para utilização, com segurança e autonomia, de espaços, mobiliários, equipamentos urbanos, edificações, transportes, informação e comunicação, inclusive seus sistemas e tecnologias, bem como outros serviços e instalações abertos ao público, de uso público ou privado de uso coletivo, tanto na zona urbana como na rural, por pessoa com deficiência ou com mobilidade reduzida (Brasil, 2015).

Sassaki (2004, p.2) também menciona que "o conceito de acessibilidade deve ser incorporado aos conteúdos programáticos ou curriculares de todos os cursos formais e não formais existentes". Para ele, "a acessibilidade não mais se restringe ao espaço físico, ou seja, à dimensão arquitetônica”. O autor classifica o conceito de acessibilidade em seis dimensões como podem ser observadas no quadro 1.

Quadro 1: Dimensões da Acessibilidade.

\begin{tabular}{|c|c|}
\hline $\begin{array}{l}\text { Dimensões da } \\
\text { acessibilidade }\end{array}$ & Definição \\
\hline Arquitetônicas & $\begin{array}{l}\text { Sem barreiras ambientais físicas em todos os recintos externos e internos da escola. } \\
\text { Barreiras: os degraus, buracos e desníveis no chão, pisos escorregadios, portas estreitas, } \\
\text { sanitários minúsculos, má iluminação, má localização de móveis e equipamentos, dentre outros. }\end{array}$ \\
\hline Comunicacionais & $\begin{array}{l}\text { Sem barreiras na comunicação interpessoal, na comunicação escrita e na comunicação } \\
\text { virtual. Ocorre com comunicação face a face, língua gestual, linguagem corporal, e comunicação } \\
\text { escrita como jornal, revista, livro, carta, etc., incluindo textos em Braille, textos com letras } \\
\text { ampliadas para quem tem baixa visão, computador e outras tecnologias para comunicar, } \\
\text { comunicação virtual -acessibilidade digital, dentre outros. }\end{array}$ \\
\hline Atitudinais & $\begin{array}{l}\text { Sem barreiras na convivência. } \\
\text { Um exemplo é a escola promover atividades de sensibilização e conscientização, a fim de } \\
\text { eliminar preconceitos, estigmas, estereótipos. }\end{array}$ \\
\hline Programáticas & $\begin{array}{l}\text { Sem barreiras invisíveis embutidas em documentos institucionais. } \\
\text { Alguns exemplos são conhecer, atualizar e eliminar as barreiras invisíveis contidas em } \\
\text { programas, regimentos, regulamentos, portarias, projetos, que possam impossibilitar ou dificultar } \\
\text { a participação plena, na vida escolar, de todos os alunos, com ou sem deficiência. }\end{array}$ \\
\hline Metodológicas & $\begin{array}{l}\text { Sem barreiras para métodos, técnicas e teorias. } \\
\text { Alguns exemplos são conhecer, aprender e aplicar a teoria das inteligências múltiplas, os vários } \\
\text { estilos de aprendizagem e aprender, produzir e utilizar materiais didáticos adequados às } \\
\text { necessidades educacionais especiais, dentre outros. }\end{array}$ \\
\hline Instrumentais & $\begin{array}{l}\text { Sem barreiras nos instrumentos e ferramentas de estudo. } \\
\text { Barreiras: qualquer bloqueio ou obstáculo que limite ou impeça o acesso, a liberdade de } \\
\text { movimento e circulação com segurança das pessoas. } \\
\text { Um exemplo é a adaptação de material didático, utilização de aparelhos, equipamentos, utensílios } \\
\text { e Tecnologia Assistiva. }\end{array}$ \\
\hline
\end{tabular}

Fonte: Sassaki (2007) - Adaptada. 
No que diz respeito à educação formal, os dilemas que as pessoas com deficiência enfrentam ainda são inúmeros por encontrarem um ambiente escolar e acadêmico sem acessibilidade e com diversas barreiras a serem transpostas. Apesar da legislação brasileira apresentar avanços e o número de estudantes na educação básica e ensino superior terem aumentado, ainda há uma discrepância entre o discurso legal-político e a realidade educacional dos/as pessoas com deficiência (PcD) (Silva, 2014).

\subsection{Desenho Universal para Aprendizagem - DUA}

O Desenho Universal para Aprendizagem - DUA surge nos anos 90, preconizado por David Rose, Anne Mayer e seus colegas, fundadores do Center for Applied Special Technology (CAST). A princípio, eles tentaram desenvolver um trabalho a partir dos diagnósticos, auxiliando os estudantes a superar suas dificuldades e comprometimentos. Contudo, com o decorrer do trabalho eles concluíram que ao invés de ajudá-los a superarem as barreiras que encontravam, a equipe deveria ajudar escolas e educadores a diminuir ou eliminar essas barreiras. (Meyer, Rose e Gordon, 2014)

Esse formato, nos traz a possibilidade de ensinar eliminando as barreiras da exclusão escolar, pois segundo Zerbato \& Mendes (2018 p. 56) “consiste em um conjunto de princípios baseados na pesquisa e constitui um modelo prático que objetiva maximizar as oportunidades de aprendizagem para todos os estudantes", utilizando-se de novas estratégias de ensino, organizando uma aprendizagem para todos, flexibilizando assim a acessibilidade dos alunos, visando satisfazer as necessidades de aprendizagem do maior número de alunos daquela sala de aula, incluindo as especificidades dos alunos público-alvo da educação especial (PAEE).

O DUA se fundamenta em três princípios para o desenvolvimento de currículos acessíveis e práticas pedagógicas inclusivas. O primeiro princípio do DUA tem como objetivo proporcionar múltiplos meios de envolvimento, e estimular a motivação para aprendizagem. O segundo proporciona múltiplos meio de representação, ou seja, as informações são apresentadas em múltiplos formatos para que todos tenham acesso. O último princípio proporciona múltiplos meios de expressão, pois permite formas alternativas de expressão e de demonstração das aprendizagens, por parte dos estudantes. Este último princípio pode ser relacionado com a avaliação da aprendizagem (Zerbato \& Mendes, 2018; Nunes \& Madureira, 2015).

Segundo Pletsch (et al., 2020) ao levar em consideração o DUA no planejamento e nas estratégias de ensino é preciso que o mesmo conteúdo esteja disponível em diferentes formas e mídias, dependendo do objetivo a ser trabalhado. Um assunto ou conceito, por exemplo, pode ser apresentado de modo interativo, usando recursos como áudio, imagem, vídeo ou animação. É fundamental que os recursos sejam pensados levando em conta a usabilidade prática dos estudantes, de preferência validados por eles próprios.

Desse modo, pode-se afirmar de acordo com os estudos de Vieira \& Cirino (2021) que os princípios do DUA aliados aos recursos e mídias disponíveis abre um leque de interações, pois possibilitam inúmeras combinações, entre texto, fala, imagem e uma ressignificação das rotas de aprendizagem, até então fixadas pelo modelo presencial. No formato remoto, essa visão da aprendizagem teve que ser repensada. Tal movimento vai de encontro com os pressupostos que o DUA amplia os processos pelos quais os alunos acessam o conhecimento.

A fim de ampliar as discussões e oferecer aportes práticos sobre a aplicação dos princípios do DUA como estratégia de acesso a aprendizagem em ambientes digitais, Pletsch et al., (2020, p. 17) sugere possibilidades e estratégias que podem ser usadas nas aulas online para incentivar a interação e a participação de todos os estudantes.

> Produção da informação em diferentes mídias: informações disponibilizadas em braile, áudio descrição, vídeos e outros recursos para pessoas com deficiências sensoriais. 
Recursos de manipulação de forma e conteúdos digitais: permite alteração do tamanho do texto e das imagens, cor usada para informar ou enfatizar, a velocidade ou tempo dos vídeos, animações, sons, simuladores e a disposição dos elementos visuais.

$>$ Recursos de ampliação de repertório: animações, vídeos, documentários, box com opinião de especialistas, box com dicas de filmes e livros para ler, tabelas, mapas conceituais e outros recursos que sirvam para ampliar o conhecimento sobre os temas apresentados em aula.

$>$ Recursos de compreensão de texto: antecipar vocabulários, destacar expressões complexas e demonstrar sua origem semântica sempre que possível.

$>$ Recursos para destaque de conceitos: grifar conceitos, destacar a relação entre ideias em um texto ou em mapas conceituais, marcar as transições nos textos e as relações na estrutura do texto, ou torná-las mais explícitas.

$>$ Recursos de imagem: ilustrações, fotografias, conceitos-chave apresentados na forma de imagens, ícones e símbolos que facilitam a navegação.

$>$ Recursos para experimentação de conceitos: simulações, exercícios de manipulação e experimentação física dos conceitos.

$>$ Recursos de organizadores avançados: mapas conceituais, glossários de imagens e textos, infográficos, linhas do tempo, planilhas e recursos que contribuam para sistematização dos conteúdos, conceitos apresentados.

$>$ Recursos para expressão dos estudantes: atividades que proponham apresentações orais, vídeos, texto de diversos formatos, desenhos e arte.

\subsection{Tecnologia Assistiva}

Compreender o que é a tecnologia, é necessário para direcionarmos o uso para fins educacionais, visto que a “tecnologia engloba a totalidade de coisas que a engenhosidade do cérebro humano conseguiu criar em todas as épocas, suas formas de uso, suas aplicações, ela é variável e contextual” (Kenski, 2012, p.23). Para o clima emergencial, esperamos que seja eficaz o uso das tecnologias digitais que estão sendo utilizadas neste período pandêmico, ainda é necessário um aprofundamento destes conceitos para que possamos alcançar a todos os estudantes, sejam estes público-alvo da educação especial - PAEE ou não.

No campo das tecnologias assistivas, especificamente na área educacional, oportunizam instrumentos formativos como facilitadores no contexto do ensino-aprendizagem, a fim de que se possa qualificar o acesso ao conhecimento na vida de pessoas e/ou alunos com deficiência. De acordo com Radabaugh (1993), para as pessoas com deficiência a tecnologia torna as coisas possíveis, e a tecnologia que é utilizada para esse público é conhecida como Tecnologia Assistiva (TA), que é um termo utilizado para "identificar todo o arsenal de recursos pedagógicos, tecnológicos e de suporte, os quais contribuem para proporcionar ou ampliar habilidades funcionais de estudantes público-alvo da educação especial, na perspectiva de promover autonomia e a inclusão" (Bersch \& Tonolli, 2006, p.89).

Visando o atendimento às necessidades educativas dos alunos com deficiência, utilizar recursos de Tecnologia Assistiva (TA) tem promovido um bom desenvolvimento e emancipação dos mesmos, tornando possível o acesso dos PAEE às mais diversas atividades escolares. A TA é considerada como:

[...] uma área do conhecimento, de característica interdisciplinar, que engloba produtos, recursos, metodologias, estratégias, práticas e serviços que objetivam promover a funcionalidade, relacionada à atividade e participação, de 
pessoas com deficiência, incapacidades ou mobilidade reduzida, visando sua autonomia, independência, qualidade de vida e inclusão social (Brasil, 2008).

O conceito de TA não deve estar restrito apenas a recursos para a sala de aula, mas para todos os ambientes da escola e fora desta, pois visa proporcionar ao estudante com deficiência, a sua autonomia, valorizando suas potencialidades, a qualidade de vida e uma maior inclusão com estímulos e motivação para que este participe ativamente do seu processo de construção de conhecimentos. Pensando assim, é notório perceber que toda a equipe escolar tem responsabilidade de criar ambientes acessíveis e inclusivos, e não apenas o professor. (Bersch, 2008)

O comitê de Ajudas técnicas-CAT diz que "a aplicação de Tecnologias Assistivas abrange todas as ordens do desempenho humano, desde as tarefas básicas de autocuidado até o desempenho de atividades profissionais" (CAT 2007, p.11), corroboramos com o autor, em que diz que as TA são organizadas e classificadas de acordo com os objetivos a quem se destina, que podem ser para auxílios para a vida diária e vida prática.

Em meio ao período pandêmico, as TA utilizadas foram ganhando um formato mais digital com as aulas remotas, tornando a inclusão dos alunos PAEE mais desafiador, pois além do uso das tecnologias assistivas no meio digital pelos alunos, o docente também necessita de uma formação que contemple esses conhecimentos, além disso “os professores precisam ser formados para uma nova didática, nova pedagogia, considerando as mudanças que ocorreram, devido à internet, na forma de ensinar e com o próprio conhecimento" (Mayrink, 2017 apud Straub, 2020, p. 40) pois, todo esse processo tecnológico, acabou por fazer emergir um universo virtual que ao mesmo tempo é paralelo ao universo físico e que é possível através de uma interconexão mundial de computadores em rede, que chamamos de ciberespaço. Segundo Mallagi e Teixeira (2019, p.68), é “[...] um sistema de comunicação eletrônica global que reúne os humanos e computadores em uma relação simbiótica, que cresce exponencialmente graças à comunicação interativa”, sendo desafiante utilizar de forma emergencial, por requerer um discernimento detalhado para incluir alunos PAEE com uso de TA digitais, sendo que mesmo com esse recurso digital, muitos destes, ainda necessitarão de outros auxílios e serviços, como o uso de órteses.

\subsection{Adaptações}

Em março de 2007 foi assinado a Convenção Internacional sobre os Direitos das Pessoas com Deficiência um documento cuja finalidade era proteger os direitos das pessoas com deficiência, resultante da Assembleia Geral das Nações Unidas, o texto engloba o reconhecimento da igualdade e não discriminação de mulheres e crianças, a conscientização da sociedade acerca das deficiências, questões referentes a acessibilidade, direito a vida, a justiça, a educação entre outros.

Ainda nesse documento, no artigo 24, referente à educação, no item 2 c), aborda sobre a necessidade de adaptações razoáveis para a pessoa com deficiência de acordo com sua individualidade. Posteriormente o Brasil promulgou o documento da convenção através do Decreto nº 6.949/2009, significando certo compromisso junto à Organização das Nações Unidas (ONU) em executar o que foi decidido em Convenção.

Outro dispositivo legal que também reforça a importância de adaptações para a pessoa com deficiência, ou como o próprio documento denomina público-alvo da educação especial (PAEE) é o Decreto n ${ }^{\circ}$ 7.611/11 que dispõe sobre o Atendimento Educacional Especializado, sem apresentar detalhamentos, apenas cita a garantia de adaptação para o ensino fundamental.

Apenas com o Estatuto da Pessoa com Deficiência, conforme a Lei 13.146/15 no inciso VI do artigo $3^{\circ}$ há uma definição clara do que seria adaptações razoáveis 
VI - Adaptações razoáveis: adaptações, modificações e ajustes necessários e adequados que não acarretem ônus desproporcional e indevido, quando requeridos em cada caso, a fim de assegurar que a pessoa com deficiência possa gozar ou exercer, em igualdade de condições e oportunidades com as demais pessoas, todos os direitos e liberdades fundamentais. (Brasil, 2015, grifo nosso).

Dessa forma percebemos que essa garantia legal remete a uma variedade de ações e práticas no contexto educacional, visto que a necessidade de cada indivíduo PAEE poderá ser única conforme seu perfil e deficiência. Considerando o contexto pandêmico, que impactou a educação brasileira desde março de 2020 e em conformidade com os dispositivos legais vivenciase desafios até outrora não imaginados, pois o ensino em todas as modalidades acontecendo de forma remota ou híbrida, ocasiona rapidez em mudanças emergenciais para tornar eficaz a educação formal, tais mudanças englobam aquisição de itens tecnológicos e habilidades no uso de aplicativos virtuais.

Durante o primeiro ano de pandemia, houve diversas publicações que além de questionar os gastos da classe docente, a carência dos alunos por recursos tecnológicos e conexão de internet, apresentam desafios do ensino remoto para a educação básica. Dentre eles destacamos, Colemarx (2020) que questiona a não universalização da internet para a escola pública, Zaidan \& Galvão (2020) também apresentam sobre a mudança de rotina dos professores ao aderirem ao home office e os custos extras.

O impacto desta realidade para o aluno PAEE é forte, pois a maioria frequenta a escola pública (INEP, 2020), neste contexto cabe a reflexão sobre as adaptações razoáveis segundo dispositivo legal para o referido grupo de alunos. Com o intuito de investigar o ensino remoto, os autores Araújo, Rego e Nascimento (2021), realizaram uma pesquisa comparando a assistência ofertada em duas escolas públicas nos estados do Piauí e da Paraíba para alunos surdos buscando refletir sobre os efeitos desse formato de ensino.

Nesta pesquisa, os autores inicialmente traçam um panorama das adaptações realizadas pelos estados do Nordeste para viabilizar o ensino remoto, e seguida relatam a execução desses "ajustes" nas escolas pesquisadas verificando os bônus e ônus, através da análise concluem as dificuldades dos alunos em acessar a internet, compreender o layout e funcionalidade da plataforma criada pelas secretarias, a carência de recursos tecnológicos e o pouco apoio familiar. Por mais que a referida pesquisa, apresenta apenas um recorte de dois lócus específicos da região Nordeste, não se pode ignorar a possibilidade de essas dificuldades também serem vivenciadas em outras escolas do país, retomando ao que diz o inciso VI do artigo $3^{\circ}$ do Estatuto, parece existir um abismo na exequibilidade o que se potencializa com os efeitos da pandemia.

\subsection{Acompanhamento}

Sabe-se que a pandemia do novo coronavírus mudou completamente a vida de milhares de pessoas pelo mundo, trazendo consigo mudanças significativas e necessárias, principalmente em relação ao convívio social. A sociedade precisou se adaptar a essa nova realidade, que não foi nada fácil, principalmente quando falamos em educação, pois ela enfrenta múltiplas dificuldades para continuar mantendo o aprendizado de seus alunos, para que estes não percam o ano letivo e tenham aprendizados relevantes. Com esse cenário, muitos gestores escolares tiveram que buscar saídas emergenciais para continuar as atividades, principalmente, com o auxílio de suportes remotos de ensino e a introdução de novas metodologias, apoiadas em tecnologias digitais. Esse novo paradigma em que a sociedade se encontra traz uma imensidão de sentimentos e angústias, isto é, sentimentos e mistos de incertezas, todos estão enfrentando grandes desafios e mudanças em suas vidas, principalmente em sua rotina, de modo que estão adaptando-se e conduzindo a vida da melhor forma possível.

Nesse contexto, é preciso lembrar que incorporar as tecnologias digitais na educação não se trata de utilizá-las somente como meio ou suporte para promover aprendizagens ou despertar o interesse dos alunos, mas sim de utilizá-las com os alunos para que construam conhecimentos com e sobre o uso dessas Tecnologias Digitais de Informação e Comunicação (TDICs). Estas por sua vez, têm alterado nossas formas de trabalhar, de se comunicar, de se relacionar e de aprender nas 
últimas décadas. Na educação, as TDICs têm sido incorporadas às práticas docentes como meio para promover aprendizagens mais significativas, com o objetivo de apoiar professores e toda a comunidade escolar na implementação de metodologias de ensino ativas, alinhando o processo de ensino-aprendizagem à realidade dos estudantes e despertando maior interesse $\mathrm{e}$ engajamento dos alunos em todas as etapas da Educação. Por outro lado, o ensino remoto no Brasil tem gerado desconforto, pois parte dos alunos e dos professores não possuem os recursos necessários para o acompanhamento de aulas online. Sob o mesmo ponto de vista, a relação dos alunos com acesso à internet, há um grande esforço para aprender a utilizar esse recurso, assim como, gerenciar o tempo dentro de casa além disso, desenvolver a disciplina para estudar de forma remota ou híbrida é complicado devido o ensino remoto ser um contexto novo para a educação.

\subsection{Barreiras tecnológicas: as que dificultam ou impedem o acesso da pessoa com deficiência às tecnologias}

Desde a virada do século, no começo dos anos 2000, ouvimos que estamos vivendo a era digital. Já quase 21 anos depois, nos vemos cada vez mais imersos na tecnologia, agora mais do que nunca potencializadas pelo isolamento social. A internet hoje é sinônimo trabalho, facilidade, localização, informação, educação. São poucas as atividades que podemos fazer sem estar online. A tecnologia digital também pode alcançar as pessoas com deficiências, pois existem aplicativos, softwares e equipamentos que possibilitam a acessibilidade a informação, entretenimento, sociabilidade entre outros benefícios. Considerando o contexto da educação, a presença da tecnologia digital é uma alternativa de recurso que potencializa no ensino de alunos PAEE, que funciona com uma solução sobre as barreiras que esse público enfrenta no processo de aprendizagem.

O Estatuto da Pessoa com Deficiência, art. $3^{\circ}$, inciso IV traz a definição de barreira:

qualquer entrave, obstáculo, atitude ou comportamento que limite ou impeça a participação social da pessoa, bem como o gozo, a fruição e o exercício de seus direitos à acessibilidade, à liberdade de movimento e de expressão, à comunicação, ao acesso à informação, à compreensão, à circulação com segurança, entre outros. Enquanto as barreiras tecnológicas são aquelas que dificultam ou impedem o acesso da pessoa com deficiências às tecnologias. (Brasil, 2015)

Estas barreiras comprometem o acesso das pessoas com deficiência à educação, e atualmente, com a pandemia, as aulas começaram a ser transmitidas virtualmente, e as aulas presenciais foram paralisadas com intuito de minimizar o contato com o vírus SARS-Cov-2 e contágios em massa.

\section{Metodologia}

De acordo com Freire (1996, p.32) o ensino e a pesquisa são indissociáveis. A pesquisa propicia conhecer o que ainda é oculto, ela é o caminho que proporciona a comunicação e o anúncio do que antes era incompreendido.

$\mathrm{O}$ presente estudo trata-se de uma pesquisa com abordagem qualitativa. Para entendermos a natureza desse tipo de pesquisa nos fundamentamos nos estudos de Triviños (2008), o qual nos relata que muitas pesquisas de caráter qualitativo não precisam se respaldar em informações estatísticas. Dessa forma, devido à natureza dos objetivos firmados neste trabalho entendemos que a pesquisa é de abordagem qualitativa, e de natureza metodológica, exploratória e bibliográfica. Neste sentido, a pesquisa exploratória intenciona prover o pesquisador de um maior conhecimento a respeito de um tema ou problema de pesquisa em perspectiva (Mattar,1994). Logo, se define-se a proposta dessa pesquisa como exploratória pelo fato de se utilizar de fontes bibliográficas e descritivas com intuito de propiciar a familiarização com os objetivos da investigação.

Mais ainda, Gil (2002) aponta que a pesquisa exploratória possui como objetivo principal o aprimoramento de ideias, descoberta de intuições, a possibilidade de explorar diferentes aspectos relativos ao fato estudado e favorecer a familiarização com o problema. Como instrumento de coleta de dados optou-se pelo levantamento bibliográfico, a fim de se obter uma melhor 
apreciação do conteúdo foco do nosso estudo.

\section{Resultados e Discussão}

Com o embargo temporário das atividades letivas presenciais, por todo o mundo, os professores e estudantes migraram para a realidade online, levando consigo metodologias e práticas pedagógicas típicas de espaços presenciais de aprendizagem, naquilo que tem sido designado por ensino remoto. Contudo, a realidade exigiu uma transição rápida em que professores precisaram se transformar em youtubers, pois é necessário gravar videoaulas, mesmo sem prática e sem formação específica, mas que aprenderam e continuam a aprender a utilizar sistemas de videoconferência, como o Google Hangout ou o Zoom e plataformas de aprendizagem, como o Moodle, o Microsoft Teams e o Google Classroom.

\subsection{Acessibilidade tecnológica e a pessoa com deficiência}

Considerando a mudança da sala de aula para o ambiente doméstico, verifica-se a necessidade de outros instrumentos tecnológicos de acesso à informação e comunicação. Como apontam Arruda, Silva e Bezerra (2020) os recursos tecnológicos que facilitariam as aulas online, como computadores, dispositivos móveis e internet não se fazem presentes nas moradias de vários alunos e professores brasileiros. E atrelado a esta necessidade dos recursos tecnológicos em si, está a inabilidade dos professores com as ferramentas digitais o que dificulta o seu próprio acesso. Deste modo, têm-se considerado um formato que exclui muitos indivíduos do processo educativo, além de não dar conta dos objetivos pedagógicos pensados no modelo presencial (Mendes et al.,2020, p. 46), porém ressaltamos ser a alternativa viável nesse processo.

Outro contexto que surge com a pandemia são as diferenças no nível de acesso de estudantes que, segundo Pill (2020) aqueles que não acessam a internet de nenhuma forma chegam a 11\% da população na faixa etária de 9 a 17 anos. A exclusão é maior entre crianças e adolescentes que vivem em áreas rurais, onde a porcentagem daqueles que não acessam a rede chega a 25\%. Nas regiões Norte e Nordeste, o percentual é $21 \%$ e, entre os domicílios das classes D e E, $20 \%$.

Segundo Silva, Bins e Rosek (2020) na educação pública além das dificuldades estruturais existem as barreiras financeiras, e a maioria das casas dos alunos da escola pública fica na periferia, onde não há aparelhos ou internet que possam dar conta das demandas de um ensino nestes modelos propostos. Dados que vão de encontro as informações dadas por Fábbio Senne, coordenador de Projetos de Pesquisas do Cetic.com a Unicef: "mesmo entre os que têm acesso, há diferença em relação à posse de um pacote de dados 3G ou acesso a Wi-Fi, o que limita o tipo de conteúdo que pode ser acessado". (NIC.BR, 2020)

Além desses pontos há diferenças entre o acesso dos estudantes aos sistemas de ensino públicos e privados. Segundo a pesquisa realizada pelo Instituto Península, em 2020 durante a pandemia, com 2.400 docentes das redes de ensino privada, estadual e municipal, de todo o Brasil, as escolas privadas afirmam prestar assistência a distância a 65,3\%, contra apenas $36,2 \%$ da rede estadual e $14,1 \%$ da rede municipal. (Victoria Oliveira, 2020)

No que diz respeito ao ensino remoto, um aspecto a ser considerado é a exclusão digital especialmente da parcela da população que apresenta alguma deficiência. A nossa pesquisa centra-se nesse aspecto, da acessibilidade digital em Tempos de Ensino Remoto. Não questionamos o potencial das tecnologias e sim as necessidades de suporte entre as pessoas, especialmente aquelas que têm alguma deficiência.

A acessibilidade tecnológica está atrelada a acessibilidade instrumental que, segundo Sassaki (2005) está relacionada ao fim das barreiras nos instrumentos e utensílios de estudo como: lápis, caneta, teclado do computador, materiais pedagógicos e as tecnologias assistivas. Correlacionado a estas características, o Estatuto da Pessoa com Deficiência, destaca no capítulo II, art. 64 sobre a acessibilidade nos sítios da internet com obtenção de financiamento de projeto com utilização de recursos públicos, convênios, ou incentivo fiscal como é descrito no inciso III, do art. 54; 
Os artigos 66, 67 e 68, da mesma lei, tratam respectivamente do papel do Poder Público no incentivo a oferta de aparelhos de telefonia fixa e móvel celular com acessibilidade, que possam ampliar os sons e todas as operações e funções disponíveis; destacam também os serviços de rádio-fusão de sons e imagens que devem permitir o uso da subtitulação por meio de legenda oculta, janela de intérprete de Libras e audiodescrição.

Nota-se que existem meios legais que facilitariam o acesso das pessoas com deficiência a educação, mas o que se observa mesmo anteriormente ao período da pandemia é que estes meios não são ofertados as pessoas com deficiência que precisam de apoio instrumental nas salas comuns e que em alguns casos, esse acesso é dado nas salas de AEE de forma presencial, o que não é possível acontecer nesse período de aulas remotas.

Seria ideal, conforme o Estatuto, no art. $68, \S 1^{\circ}$ "formatos acessíveis de arquivos digitais que possam ser reconhecidos e acessados por softwares leitores de telas ou outras tecnologias assistivas, que permitam leitura de voz sintetizada, ampliação de caracteres, diferentes contrastes e impressão em braile" Este artigo caracteriza uma forma de mediar a educação das pessoas com deficiências com recursos tecnológicos, que seriam bem proveitosos se fossem disponibilizados desde as séries iniciais para alunos com deficiência.

Sobre as barreiras que impedem o acesso aos ambientes digitais, os autores supracitados destacam 03 (três) degraus que precisam ser superados, como pode ser observado na figura 1.

Figura 1: Barreiras que impedem o Acesso aos Ambientes Digitais.

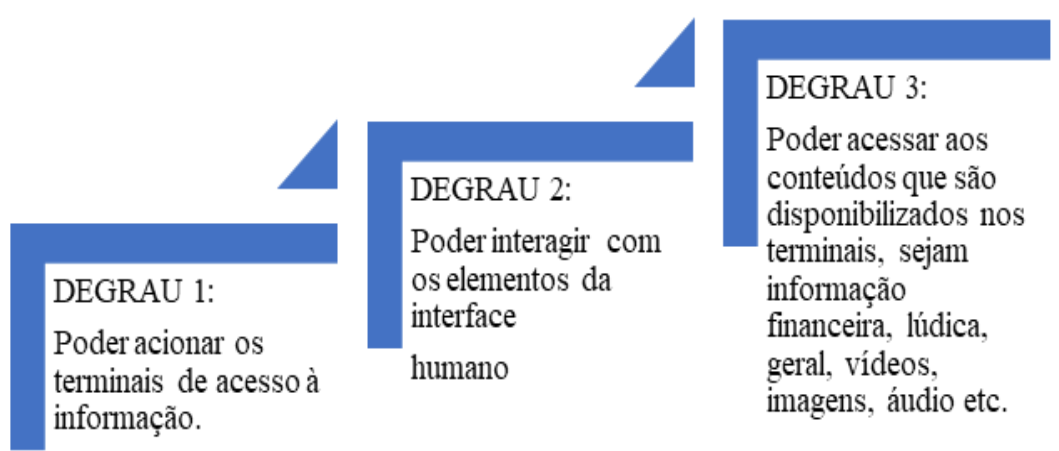

Fonte: Torres et.al., (2002) - Adaptada.

Em outro estudo, Torres e Mazzoni (2004) reiteram que para se construir um espaço e conteúdos digitais acessíveis a todos, respeitando-se as limitações (tanto orgânicas quanto de equipamento) que essas pessoas possam ter, é necessário combinar a apresentação da informação de formas múltiplas (flexibilização das formas de apresentação), com o uso de ajudas técnicas (tais como sistemas de leitura de tela, sistemas de reconhecimento da fala, simuladores de teclado etc.) que maximizam as habilidades dos usuários com limitações associadas a deficiências orgânicas.

Hoje, as tecnologias por videochamadas, reuniões virtuais por meio de diferentes plataformas, ligações telefônicas mais longas que substituem as mensagens rápidas se tornam alternativas para manter a proximidade com o outro. (Silva, Bins e Rosek, 2020). Mas o que se nota é que mesmo com empenho, dedicação e com as leis a favor da inclusão das pessoas com deficiência alguns ainda ficarão à margem, pois a sociedade, nem as instituições de ensino não oferecem as mesmas possibilidades de acesso às tecnologias mais modernas para alunos com alguma deficiência.

Assim, sempre que estes direcionamentos não forem assegurados existirão barreiras no acesso à tecnologia e consequentemente a educação que está ocorrendo pelos meios digitais. 


\subsection{Barreiras ou dificuldades do Ensino Remoto para pessoas com deficiências}

No quadro 2 buscamos expor a sobre as dificuldades de algumas deficiências baseadas na literatura acadêmica que evidencia as especificidades desse público e em dados empíricos gerados através da investigação nossa em lócus, citados em outras seções neste artigo.

Quadro 2: Dificuldades do Ensino Remoto para pessoas com deficiências

\begin{tabular}{|c|c|}
\hline Tipos de Deficiência & Dificuldades no Ensino Remoto \\
\hline $\begin{array}{c}\text { Surdez } \\
\text { (usuário da Libras) }\end{array}$ & $\begin{array}{l}\text { O aluno com surdez, necessita de uma adaptação linguística, oferecida diretamente por um intérprete } \\
\text { educacional, currículo adaptado, e tecnologias assistivas voltadas para exploração de uso visual, visto } \\
\text { que sua língua natural, é de natureza visual-motora. Uma das maiores dificuldades na inclusão escolar } \\
\text { destes alunos no ensino remoto se dá por questões metodológicas que muitas vezes não são } \\
\text { adaptadas, e que erroneamente acha-se que o intérprete educacional resolveria a questão } \\
\text { comunicacional. Além dos problemas recorrentes ao acesso nas plataformas, por problemas na } \\
\text { conexão, qualidade da transmissão com possibilidade de congelamento de screen constantemente, } \\
\text { fazendo com que a comunicação em Língua Brasileira de Sinais-Libras se perca, tornando-o } \\
\text { insatisfatório. }\end{array}$ \\
\hline Baixa visão & $\begin{array}{l}\text { Apesar de escutarem os diálogos, como fazer para que acompanhem o chat e as apresentações dos } \\
\text { docentes, e as atividades escritas com apoio do Braille? É possível verificar quais plataformas } \\
\text { possibilitam aumentar a fonte desses recursos, adaptar as apresentações ou disponibilizá-las aos } \\
\text { alunos com antecedência em um formato editável ou que possa ser lido por um software leitor. Existe } \\
\text { uma diversidade de modelos pedagógicos adotados no ensino presencial que podem ser adaptados } \\
\text { para serem realizados a distância de forma a se atingir os objetivos pedagógicos com qualidade. }\end{array}$ \\
\hline Intelectual & $\begin{array}{l}\text { As dificuldades encontradas podem o próprio acesso e utilização das tecnologias, bem } \\
\text { como habilidades de leitura e escrita. Esses entraves podem ser substanciados através da utilização de } \\
\text { adaptações pedagógicas e apoio familiar contínuos para potencializar o estudo, possibilitando novas } \\
\text { formas de apropriação dos conhecimentos e garantindo um ensino que atenda às suas especificidades } \\
\text { por meio de metodologias diversificadas e interdisciplinares. }\end{array}$ \\
\hline $\begin{array}{l}\text { Transtorno do } \\
\text { Espectro do } \\
\text { Autismo }\end{array}$ & $\begin{array}{l}\text { As pessoas com TEA apresentam inúmeras dificuldades no que se refere ao acesso ao conhecimento } \\
\text { escolar, e dentro do ensino remoto essas defasagens se amplificam. Elas apresentam dificuldades na } \\
\text { comunicação social, na linguagem receptiva e expressiva, nas funções executivas e no tempo de } \\
\text { atenção e concentração. No ensino remoto, as atividades precisam levar em consideração os } \\
\text { interesses do aluno, preparar junto com a família um plano de trabalho, uma espécie de rotina. Nas } \\
\text { aulas síncronas é interessante que a turma esteja com o microfone desligado para não gerar ruídos e } \\
\text { incômodo sensorial, vídeos mais curtos e com bastante imagens e mapas conceituais para assimilação } \\
\text { de conceitos da área estudada, outra estratégia importante é antecipar o que será trabalhado nas aulas } \\
\text { seguintes. A escola também pode oferecer recursos estruturados para trabalhar as habilidades } \\
\text { necessárias, seja funcionais ou acadêmicas. As atividades online/impressas devem conter enunciados } \\
\text { em caixa alta, objetivos e claros; uma atividade por página, com imagens e ilustrações a fim de } \\
\text { facilitar a compreensão. }\end{array}$ \\
\hline Deficiente Físico & $\begin{array}{l}\text { Com os mais diversos tipos de deficiências físicas, alguns alunos que tenham, principalmente } \\
\text { comprometimento nas funções motoras inferiores, que são necessárias para o uso de computadores ou } \\
\text { smartphones, será prejudicado, por não conseguir manusear determinados recursos tecnológicos } \\
\text { usados no ensino remoto, precisando as vezes de uso de órteses, próteses, mesas adaptadas, e o apoio } \\
\text { de recursos tecnológicos mais autônomos, pois não há no ensino remoto auxílio de recursos humanos } \\
\text { capazes de garantir o pleno acesso dos mesmo estando em suas casas. }\end{array}$ \\
\hline
\end{tabular}

Fonte: Dados da pesquisa.

Desse modo, nota-se que a educação sendo um direito social e que permanentemente há necessidade de uma reflexão sobre a possibilidade de utilização do ensino híbrido como um instrumento estratégico e proporcionar a docentes e discentes a aquisição de conhecimentos que permita que eles demonstrem capacidade crítico-reflexiva, habilidades e competências para o desenvolvimento de seus papéis. A priori, as escolas devem problematizar e repensar uma forma de ensinar e aprender e a tecnologia pode e deve ser uma aliada do ensino-aprendizagem e ser capaz de proporcionar diversos benefícios. Assim, a 
expectativa é que seu uso se torne comum.

Com isso, pode-se concluir que, perante toda essa situação pandêmica em que nos encontramos é complexa e desafiadora diversas dificuldades também se fazem presentes no cenário escolar e que é inegável a necessidade dos docentes e discentes de se reinventarem. Mais ainda, desafia equipes diretivas, professores, estudantes e famílias. Tudo isso faz repensar, de certo modo, atitudes que os cidadãos deveriam ter para uma melhor desenvoltura da educação e da sociedade.

\section{Considerações Finais}

Com a pandemia ficou mais ainda evidenciado os graves problemas existentes na educação e na sociedade, ressaltando como as pessoas com deficiências têm sido frequentemente excluídas. Também tem servido para demonstrar que as medidas de acessibilidade são passíveis de serem utilizadas, exigindo especialmente um olhar atento do corpo docente e de profissionais das instituições de ensino, sustentados na perspectiva da acessibilidade atitudinal.

A acessibilidade digital, no ensino remoto, fez com que diversos tipos de tecnologias fossem sendo relocadas para outros fins, e não apenas para entretenimentos, por exemplo, o uso de aplicativos como Whats App e YouTube, que são plataformas de comunicação e interação, e eram mais utilizados para entreter, e hoje são vistos também como ferramentas de transmissão de conteúdos escolares e interação. $\mathrm{O}$ uso das plataformas de interação com o intuito de dar continuidade ao ano letivo, como as mídias sociais, fazem parte de nosso cotidiano, só que ainda carece por parte dos profissionais e alunos, habilidades para o uso produtivo dessas mídias em sala de aula, em prol da construção de saberes dos estudantes.

Trabalhar na perspectiva da educação inclusiva com esses estudantes salienta mudanças importante, pois, se outrora, eram atendidos exclusivamente por escolas especiais, agora pela abordagem da inclusão, a meta é que esses alunos frequentem as escolas regulares, tendo o apoio da equipe do Atendimento Educacional Especializado em Sala de Recursos Multifuncionais. Também compreendemos o quão o acesso precário à tecnologia e à internet causam desvantagens para as pessoas com deficiência no requisito aprendizagem, pois a tímida adaptação de materiais para a modalidade virtual e as barreiras que existem dentro do próprio ambiente digital (sites e plataformas) dificultam ou impedem o acesso da pessoa com deficiência às informações e conhecimento.

Ademais, há uma preocupação de desenvolver estratégias, recursos didáticos mais adequados e competências a serem desenvolvidas nos estudantes. Isso é de extrema importância, pois está efetivado em lei a contemplação e o desenvolvimento de competências e habilidades relacionadas ao uso crítico e responsável das tecnologias digitais tanto de forma transversal quanto de forma direcionada tendo como fim o desenvolvimento de competências relacionadas ao próprio uso das tecnologias, recursos e linguagens digitais.

A virtualização dos sistemas educativos evidenciou inquietação, fragilidades e acima de tudo, desigualdades estruturais e econômicas da sociedade brasileira e mundial que precisam e precisarão com o passar dos dias se adequar a uma nova finalidade, com a responsabilidade social, não apenas de garantir o ensino (no caso das instituições de educação), mas, sobretudo, o conhecimento em si dos sujeitos envolvidos nesse processo de educar.

Com tudo isso, a temática abordada é de grande importância para o crescimento da educação, por isso, a opção pelo tema, advém da necessidade de haver mais discussão e conhecimento sobre. Isto porque muitas pessoas desconhecem a realidade da acessibilidade ou a falta dela para os alunos frente ao ensino remoto e que pode levar a novos desafios como, a evasão escolar, caso considerado "comum" no ensino presencial e que tem se tornado algo complexo nos dias atuais pela falta de acessibilidade as tecnologias de comunicação e informação, deixando os discentes desmotivados e a desistirem de estudar, isto é, o interesse pelo tema em questão surgiu com o desejo de conhecer mais sobre a temática e pelo fato de ainda ser um campo aberto para pesquisas e ainda não ser um campo consolidado em muitas áreas de pesquisas. 


\section{Referências}

Araújo, N. F. M. de; Rego, K. K. A. \& Nascimento, J. F. (2021). O ensino remoto para alunos surdos: estratégias e possibilidades em tempos de pandemia. In Melo, J. A. B. de; Aragão, P. C. (Orgs). Práticas Pedagógicas em Tempos de Pandemia - contribuições das diversas disciplinas do currículo para a formação de professores. São Paulo: Mentes Abertas, pp. 71-90.

Arruda, G. Q. de; Silva, J. S. R. da \& Bezerra, M. A. D. (2020, dezembro). O uso da tecnologia e as dificuldades enfrentadas por educadores e educandos em meio a pandemia. Anais VII CONEDU - Edição Online. Campina Grande, PB, Brasil: Realize Editora, https://editorarealize.com.br/artigo/visualizar/69162 Bersch, R. (2006). Tecnologia assistiva e educação inclusiva. In: Ensaios Pedagógicos, Brasília: SEESP/MEC, p. 89-94.

Bersch, R. (2008). Introdução à Tecnologia Assistiva. CEDI, Centro Especializado em Desenvolvimento Infantil. Porto Alegre.

Brasil (2000). Lei $n^{\circ}$ 10.098, de 19 de dezembro de 2000. Estabelece normas gerais e critérios básicos para a promoção da acessibilidade das pessoas portadoras de deficiência ou com mobilidade reduzida, e dá outras providências. Diário Oficial da União, Brasília, DF, Seção 1 - Eletrônico - 20/12/2000, Página 2.

Brasil. (2008). Política Nacional de Educação Especial na Perspectiva da Educação Inclusiva. Brasília.

Brasil. (2009). Decreto n. 6.949, de 25 de agosto de 2009. Promulga a Convenção Internacional sobre os Direitos das Pessoas com Deficiência e seu Protocolo Facultativo, assinados em Nova York, em 30 de março de 2007. Diário Oficial da União, Brasília, DF, ano 146, n. 163, 26 ago. 2009. Seção 1, p. 3-9.

Brasil. (2011) Decreto $n^{o}$ 7.611, de 17 de novembro de 2011. Dispõe sobre a educação especial, o atendimento educacional especializado e dá outras providências. Diário Oficial da União, Brasília, 18 de novembro de 2011, Seção 1, p.12.

Brasil. (2012). Secretaria Nacional de Promoção dos Direitos da Pessoa com Deficiência. Cartilha do censo 2010: pessoas com deficiência. Brasília,

Brasil. (2015). Lei $n^{o} 13.146$ de 6 julho de 2015. Institui a Lei Brasileira de Inclusão da Pessoa com Deficiência (Estatuto da Pessoa com Deficiência). Diário Oficial da União, Brasília, 07 de julho de 2015. Seção 1, p.2-11. Brasília.

Cat. (2007) Comitê de Ajudas Técnicas Secretaria Especial dos Direitos Humanos da Presidência da República (CORDE/SEDH/PR. Ata da Reunião VII.

Colemarx. (2020) Em defesa da educação pública comprometida com a igualdade social: porque os trabalhadores não devem aceitar aulas remotas. Programa de Pós-Graduação em Educação - PPGE. Universidade Federal do Rio de Janeiro. Rio de Janeiro.

Freire, P. (1996). Pedagogia da autonomia: saberes necessários à prática pedagógica. São Paulo: Paz e Terra.

Gil, A. C. (2002). Como elaborar projetos de pesquisa. São Paulo: Atlas.

Instituto Nacional de Estudos e Pesquisas Educacionais Anísio Teixeira. (2020). Sinopse Estatística da Educação Básica 2019. Brasília: Inep http://portal.inep.gov.br/web/guest/sinopses-estatisticas-da-educacao-basica.

Kenski, V. M. (2012) Educação e tecnologia: O novo ritmo da informação. 8 ed. Campinas: Papirus.

Mattar, F. N. (1994). Pesquisa de marketing: metodologia, planejamento, execução e análise. 2a. ed. São Paulo: Atlas, 2v., v.2. 1994.

Mallagi, V.; Teixeira, A. C. (2019) Comunicação, tecnologias interativas e educação: (re)pensar o ensinar-aprender na cultura digital. Curitiba: Appris.

Mendes, A., Vinagre, A. B., Amorim, A., Chaveiro, E., Machado, K., Vasconcellos, L. C. F. D., \& Gertner, S. (2020). Diálogos sobre acessibilidade, inclusão e distanciamento social: territórios existenciais na pandemia.

Meyer, A.; Rose, D. H. \& Gordon, D. (2014) Universal design for learning: Theory and Practice. Wakefield, MA: CAST Professional Publishing.

Mingus, Mia. (2011) Changing the Framework: Disability Justice. Documento eletrônico. https://leavingevidence.wordpress.com/2011/02/12/c hanging-theframework-disability-justice/

Mingus, Mia. (2018) Disability Justice is Simply Another Term for Love. Documento eletrônico.: https://leavingevidence.wordpress.com/2018/11/03/di sability-justice-is-simply-another-term-for-love/

Nic.br (2020). Núcleo de Informação e Coordenação do Ponto BR - NIC.br. FALTA acesso à internet para faixa de 9 a 17 anos. https://www.nic.br/noticia/namidia/falta-acesso-a-internet-para-faixa-de-9- a-17-anos.

Nunes, C; Madureira, I. (2015) Desenho Universal para a Aprendizagem: Construindo práticas pedagógicas inclusivas. Invest. Práticas, Lisboa, v. 5, n. 2, pp. 126-143, set.

Pill, Débora. (2020). ECOA, UOL. Educação na pandemia de priorizar reflexão e cidadania, dizem experts. https://www.uol.com.br/ecoa/ultimasnoticias/2020/06/13/educacao-na-pandemia-deve-priorizar-reflexao-e-cidadania-dizem-experts.htm

Pletsch, M. D.; Leite, L. P. (2017) Análise da produção científica sobre a inclusão no ensino superior brasileiro. Educar em Revista, n. SPE. 3, pp. 87-106.

Pletsch, M. D., de Souza, I. M. D. S., Moreira, S. C. P., \& de Assis, A. R. (2020). APRESENTAÇÃO PRIMEIRA EDIÇÃO ESPECIAL: EDUCAÇÃO E DEMOCRACIA EM TEMPOS DE PANDEMIA. Revista Interinstitucional Artes de Educar, 6, 4-11.

Radabaugh, M. P. Nidrr's Long Range Plan - Technology for Access and Function Research Section Two: NIDDR Research Agenda Chapter 5: Technology For Access And Function - http://www.ncddr.org/rpp/techaf/lrp_ov.html. 1993

Sassaki, R. K. (2004). Pessoas com deficiência e os desafios da inclusão. Revista Nacional de Reabilitação, 30(09). 
Research, Society and Development, v. 10, n. 4, e60010414966, 2021

(CC BY 4.0) | ISSN 2525-3409 | DOI: http://dx.doi.org/10.33448/rsd-v10i4.14966

Sassaki, R. K. (2007). Nada sobre nós sem nós: da integração à inclusão. Rev. Nac. Reabil, 10(57), pp. 8-16.

Silva, J. S. S. (2014) Acessibilidade, barreiras e superação: estudo de caso de experiências de estudantes com deficiência na educação superior. Dissertação (Mestrado em Educação) - Universidade Federal da Paraíba, João Pessoa.

Silva, K. W. da, Bins, K. L. G., \& Rozek, M. (2020). A educação especial e a covid-19: aprendizagens em tempos de isolamento social. Educação, 10(1), 124136

Silva, R. S., \& Amaral, C. L. C. (2020). A educação inclusiva no ensino de ciências e matemática. Communitas,4(7), pp. 281-294.

Silva, R. S., \& Amaral, C. L. C. (2020). Percepção de professores de química face à educação de alunos com deficiência visual: dificuldades e desafios. South American Journal of Basic Education, Technical and Technological,7(1), pp.108-129.

Silva, R. S., de Sousa, M. V., \& da Silva, I. R. (2020). Inclusão escolar de crianças com Síndrome de Down na educação infantil. Revista Amor Mundi, 1(3), $35-46$.

Simões, G. S., Silva, R. S., \& Amaral, C. L. C. (2021). Transposition of scientific knowledge in teaching Mathematics to the blind. Research, Society and Development, 10(3), e59810310395. https://doi.org/10.33448/rsd-v10i3.10395

Straub, Sandra Luzia Wrobel. Laboratórios de Informática das Escolas Públicas Estaduais Mato-Grossenses: uma análise discursiva da realidade educacional. Cáceres: UNEMAT Editora, 2020. pp. 35-47.

Torres, E. F., \& Mazzoni, A. A. (2004). Conteúdos digitais multimídia: o foco na usabilidade e acessibilidade. Ciência da informação, 33(2).

Triviños, A. N. S. (2008) Introdução a pesquisa em ciências sociais: a pesquisa qualitativa em educação.1. ed.-17. reimpr. São Paulo: Atlas.

Victória Oliveira, M. P. (2020). Pesquisa monstra sentimento de professores em meio à pandemia do coronavírus. https://porvir.org/pesquisa-mostra-osentimento-de-professores-em-meio-a-pandemia-do-coronavirus.

Vieira, L. A., Cirino, R. M. B., \& de Farias, E. R. S. (2021). As tecnologias educacionais na promoção de práticas pedagógicas inclusivas. Brazilian Journal of Development, 7(2), 20551-20561.

Zaidan, J. de M.; Galvão, A. C. (2020). Covid-19 e Os Abutres Do Setor Educacional: A Superexploração Da Força De Trabalho Escancarada. In Augusto, Cristiane Brandão; Santos, Rogerio Dultra dos. Pandemias e pandemônio no Brasil. São Paulo: Tirantlo Blanch.

Zerbato, A. P.; Mendes, E. G. (2018) Desenho universal para a aprendizagem como estratégia de inclusão escolar. Educação Unisinos, v.22, n. 2, pp. 147-155, abr./ jun. Doi: 10.4013/edu.2018.222.04. 